\title{
Cryptococcal Antigenaemia among Treatment-Naïve Adult HIV-Infected Nigerian Patients
}

\author{
Taiwo Modupe Balogun*, Mbang Okokon, Faleye Dasola, Esuola Joseph Oyetubosun, \\ Adewolu Abimbola, Basil Bonaventure \\ Antiretroviral Therapy Clinic, Haematology Department, Lagos State University Teaching Hospital, Lagos, Nigeria \\ Email: "taiwo_modupe@yahoo.com
}

Received 2 December 2015; accepted 23 February 2016; published 26 February 2016

Copyright (C) 2016 by authors and Scientific Research Publishing Inc. This work is licensed under the Creative Commons Attribution International License (CC BY). http://creativecommons.org/licenses/by/4.0/

c) (i) Open Access

\begin{abstract}
Background: There is a high burden of HIV-related cryptococcal meningitis in Sub-Saharan Africa and it is a leading cause of morbidity and early mortality among severely immunocompromised patients. Objectives of the Study: This study was carried out to determine the prevalence of cryptococcal antigen ( $\mathrm{CrAg}$ ) and the relationship of positivity to $\mathrm{CD} 4+\mathrm{ve} \mathrm{T}$ cell counts and WHO clinical stage among severely immunocompromised treatment naïve adult HIV-infected Nigerian patients. Methods: This was a hospital based cross sectional and prospective study carried out among newly diagnosed and confirmed HIV infected patients. Bio data of consenting consecutive subjects was collected by the attending physician using structured questionnaire. Rapid point of care lateral flow assay kits (IMMY, USA) was used to screen plasma samples from subjects strictly following manufacturer's instructions. Data were analysed with statistical package for social sciences (spss 15.0) software. Results were presented in simple tables with frequencies and percentages while statistical significance was taken to be $p$ value $\leq 0.05$. Results: Of 432 subjects, there were 184 (42.6\%) males and $248(57.4 \%)$ females in the study. The median CD4 count of the subjects was 74 (range 6 - 1264) cells/ul. Seven (1.6\%) of the subjects were positive for cryptococcal antigen (CrAg) and all were females $(100 \%)$. Six $(85.7 \%)$ of $\mathrm{CrAg}$ positives had $\mathrm{CD}^{+} \mathrm{T}$ cell count less than 100 cells, while $1(14.3 \%)$ had count above 200 cells/ul. The WHO clinical stage of studied patients was; stage I 163 (37.7\%), stage II 132 (30.6\%) stage III 95 (22.0\%) and stage IV 42 (9.7\%). Among the CrAg positive subjects, $3(42.9 \%)$ were in WHO clinical stage 1 while $4(57.1 \%)$ were in stage II disease. Conclusion: The observed overall prevalence of $\mathrm{CrAg}$ positivity among studied patients was low but occurred most frequently among the severely immunocompromised subjects. Advancement in WHO clinical stage was not a predicting risk factor for cryptococcal antigenaemia in studied adult HIV infected patients.
\end{abstract}

${ }^{*}$ Corresponding author.

How to cite this paper: Balogun, T.M., Okokon, M., Dasola, F., Oyetubosun, E.J., Abimbola, A. and Bonaventure, B. (2016) Cryptococcal Antigenaemia among Treatment-Naïve Adult HIV-Infected Nigerian Patients. World Journal of AIDS, 6, 1-7. http://dx.doi.org/10.4236/wja.2016.61001 
Keywords

HIV, Cryptococcal Antigen, Infected Adults, Nigeria

\section{Introduction}

Cryptococcosis is one of the most common AIDS defining opportunistic infections and a leading cause of mortality [1]. Cryptococcal neoformans (C. neoformans), an encapsulated yeast, is the major opportunistic pathogen and a leading cause of mortality in AIDS patients in much of the developing world [2] [3]. C. neoformans is a soil organism and the dominant causative agent of cryptococcosis which affects any organ in the body, but most often the lungs and the central nervous system, causing life threatening meningitis. Infection with C. neoformans is acquired through the inhalation of its spores. Approximately 10\% of AIDS patients have been reported to develop cryptococcal disease [4]. Cryptococcal meningitis (CM) is a leading cause of morbidity and mortality among HIV/AIDS patients in sub Saharan Africa [5] [6] and it remains an AIDS defining illness. It is reportedly common among patients with immunosuppression and could also be the initial manifestation of HIV infection [6]. Cryptococcal meningitis is reportedly a leading contributor to early mortality in the first few months of antiretroviral therapy, accounting for up to $20 \%$ of all deaths [7] [8]. A high mortality rate due to CM has been reported among patients recently initiated on ART despite an expanding access in South Africa [9]. Cryptococcal antigen (CrAg) screening prior to commencing antiretroviral therapy especially in patients with CD4 count $\leq$ 100 cells/ul is found highly effective at identifying those at risk of cryptococcal meningitis and death [10].

There is a high cryptococcal burden in Sub Saharan Africa and South East Asia where studies reveal 10\% - 18\% of HIV infected first time clinic attendees have a positive cryptococcal antigen on routine screening [11]. A study in Benin City, South south region of Nigeria reveals cryptococcal antigenaemia of $12.7 \%$ among antiretroviral therapy naïve AIDS patients [12]. Cryptococcal antigen (CrAg), a biologic marker of cryptococcal infection, is detectable in sera within a median of 3 weeks (range 5 - 234 days) before symptoms of meningitis appear and can be screened to prevent this life threatening disease [13] [14]. CrAg in the serum usually is indicative of systemic disease and correlates with fungal burden. Patients with CD4 counts less than 100 cells/ul most commonly are positive for this antigen. This period of asymptomatic antigenemia provides a window of opportunity to treat patients and potentially prevent fatal cryptococcal meningitis. In the asymptomatic phase, the diagnosis of cryptococcosis and prevention of cryptococcal meningitis is very feasible with the use of some modern rapid screening assay methods [13]. Early diagnosis of subclinical or clinical cryptococcosis is a crucial aspect of infectious disease control, especially in resource limited settings. Thus, screening persons for cryptococcal antigenemia prior to initiating ART can identify those at highest risk for mortality due to cryptococcosis [14]. This might permit implementation of a targeted pre-emptive treatment strategy. The limited use of strategies to diagnose cryptococcal disease early in HIV infection, prior to the onset of meningitis, likely contributes to ongoing morbidity and mortality, particularly in low-resource settings. Human Immunodeficiency Virus (HIV) is a retrovirus and a causative agent of Acquired Immunodeficiency Syndrome. The route of transmission of HIV is mainly sexual. Transmission is through unprotected sex which could be homosexual or heterosexual [15]. Other important routes of transmission of HIV include the transfusion of contaminated blood or blood products, sharing of sharp objects such as needles, blades, knives. Vertical transmission is from mother to child in pregnancy, at childbirth, during delivery and through breast feeding [16]. The high risk factors for HIV infection include having unprotected sexual intercourse, keeping of multiple sex partners and involvement with extramarital sex. The clinical features of HIVdisease include persistent generalized lymphadenopathy, fever, weight loss, mucocutaneous lesions such as seborrheic dermatitis, fungal nail infections, recurrent oral ulcerations, herpes zoster, as well as unexplained chronic diarrhea, pulmonary tuberculosis, oesophagial candidiasis and cryptococcal meningitis [15]. This study was carried out to assess the magnitude and risk of cryptococcal disease in HIV positive patients in Lagos, Nigeria. Based on obtained results, appropriate recommendations for the introduction of targeted screening for CrAg and possibly pre-emptive antifungal treatment of HIV-infected patients at an early stage would be made. This would reduce the incidence of usually fatal cryptococcal meningitis among this cohort of patients.

\section{Objectives of the Study}

1) To determine the seroprevalence of cryptococcal antigenaemia among treatment naïve adult HIV-infected 
patients with severe immunosuppression (CD4 count $\leq 100$ cells/ul).

2) To determine the effect of CD4+ve T cell count variation on positivity for CrAg among treatment naive adult HIV positive patients.

3) To make recommendations based on obtained results, for routine CrAg screening and possibly the use of antifungal pre-emptive treatment among HIV positive patients in Nigeria.

\section{Materials and Methods}

A cross-sectional prospective hospital based study was carried out among newly diagnosed antiretroviral therapy naïve HIV infected patients. The study was done over a period of 24 months from July 2012 to June 2014 at the HIV clinic of a tertiary care (740 beds) hospital in Lagos, Nigeria. The study protocol was approved by the institutional review board. This state owned tertiary health care facility and referral centre is situated at Ikeja, the capital of Lagos which is a commercial nerve centre located South west Nigeria. As a tertiary hospital in Lagos, which is the largest urban area in Nigeria, this hospital serves an estimated population of over 21 million residents A structured questionnaire administered by the attending physician was used to collect demographic data of age, gender, educational qualification, Tuberculosis (TB) status, WHO clinical classification after evaluation while CD4+ve T cell count was recorded on the same form in the laboratory. After counseling, the diagnosis of HIV was made using capillary blood from patients and following the Nigerian National serial algorithm with two rapid kits: Determine and Unigold. CD4+ve T cell counts of patients were determined with the Cyflow counter method (Partec, Germany). After an informed consent, 2 - 3 millilitres of whole venous blood was collected from the patient into an ethylenediaminetetraacetic acid (EDTA) containing bottle. The sample was allowed to settle in the refrigerator at the laboratory of the HIV clinic of the Lagos State University Teaching Hospital (LASUTH), South west Nigeria. Plasma was pipette from samples into cryovials and screened for CrAg using WHO recommended Lateral Flow Assay (IMMY, USA) which is a rapid point of care dipstick assay for the diagnosis of cryptococcal disease. The simple to use assay was used for running this screening while strictly observing the manufacturer's instructions. The point of care Lateral Flow Assay (LFA) has 100\% sensitivity and 94\% specificity. The LFA was performed in 5 easy steps and objective qualitative results were obtained within 10 minutes. The presence of two visible bands on the dipstick indicates a positive result on the test plasma which is in keeping with the manufacturer's positive control. The qualitative test result was interpreted as nonreactive (negative) if it showed only one visible band on the dipstick. Inclusion criteria for subjects in this study were age 18 years and above, freshly diagnosed and confirmed positive for HIV, just enrolled into care and treatment naive. The exclusion criteria were age less than 18 years, not confirmed for HIV and treatment experienced. Obtained data was analysed using the Statistical package for Social Sciences (SPSS) version 15.0 software to generate frequencies percentages. $\mathrm{P}$ value $\leq 0.05$ was considered statistically significant in group comparisons. Results were presented in tables.

\section{Results}

Four hundred and thirty two confirmed HIV patients were tested for cryptococcal antigen. There were 184 (42.6\%) men and 248 (57.4\%) women studied. Seven (1.6\%) of the subjects were positive for cryptococcal antigen. The WHO clinical stage of studied patients was; stage I 163 (37.7\%), stage II 132 (30.6\%) stage III 95 (22.0\%) and stage IV 42 (9.7\%). The age of the subjects ranged from $18-75$ years with a mean of $38.15 \pm$ SD 9.53. Majority 196 (45.4\%) of the subjects were in the age group 29 - 39 years. Two hundred and sixty six (62\%) had CD4+ve T cell count less than 100 cells/ul, 100 (23.3\%) between 100 and 199 cells and 63 (14.7\%) had above 200 cells/ul as in Table 1. In Table 2, majority 4 (57.1\%) of cryprococcal antigen positive subjects were in the age group 29 - 39 years and were all females. Most 5 (71.4\%) of the $\mathrm{CrAg}+\mathrm{ve}$ subjects had secondary education. Six (85.7\%) of CrAg positive patients had CD4+ve T cell count below 100 cells/ul while one (14.3\%) had count above 200 cells. Three (42.9\%) of the CrAg positive patients were in WHO clinical stage 1 while 4 (57.1\%) were in stage II with none in stages III and IV. None of the CrAg positive patients had active TB as in Table 3. Mean CD4 count was112 (range 06 - 1264) cells/ul and median was 74.

\section{Discussion}

Our study examined the prevalence of cryptococcal antigenaemia and its relation to CD4+ve T cell counts and 
WHO clinical staging among treatment naïve HIV positive Nigerian adults. We observed a cryptococcal antigenaemia rate of $1.6 \%$. Our observed overall low cryptococcal antigenaemia of $1.6 \%$ among treatment naïve HIV positive patients is comparable with previous reports from Shika in Nigeria $2.2 \%$ [17], Tanzania 3\% [18] and USA 2.9\% [19]. However our overall prevalence value in this study is lower than some reports from Nnewi 13.1\% [20] South east, and Benin12.7\% [12] South south part of Nigeria as well as Kenya 11\% [21], Uganda 5.7\% [22], Indonesia 7.1\% [23] and Thailand 9.2\% [24]. The observed differences in prevalence rates of cryptoccocal antigen positivity among HIV infected persons in the various studies cited may be explained by differences in sample

Table 1. Sociodemographic characteristics, WHO clinical staging, CD4+ve T cell levels and cyrptococcal antigen status of patients.

\begin{tabular}{|c|c|c|c|}
\hline Parameters & & n(\%) & P value \\
\hline \multirow{5}{*}{ Age Group (years): } & $18-28$ & $63(14.6)$ & \multirow{5}{*}{0.00} \\
\hline & $29-39$ & $196(45.4)$ & \\
\hline & $40-49$ & $122(28.2)$ & \\
\hline & $50-59$ & 47 (10.9) & \\
\hline & $\geq 60$ & $4(0.9)$ & \\
\hline Total & & $432(100)$ & \\
\hline Mean Age & $38.15 \pm 9.5$ Years & & \multirow{4}{*}{0.002} \\
\hline \multirow{2}{*}{ Gender } & Male & $184(42.6)$ & \\
\hline & Female & $248(57.4)$ & \\
\hline Total & & $432(100)$ & \\
\hline \multirow{4}{*}{ WHO Clinical Staging } & Stage I & $163(37.7)$ & \multirow{5}{*}{0.00} \\
\hline & Stage II & $132(30.6)$ & \\
\hline & Stage III & $95(22.2)$ & \\
\hline & Stage IV & $42(9.7)$ & \\
\hline \multirow{3}{*}{ CD4+ve T Cell Count } & $0-99$ & $266(62)$ & \\
\hline & $100-199$ & $100(23.3)$ & 0.000 \\
\hline & $\geq 200$ & $63(14.4)$ & \multirow{3}{*}{ Range (6 - 1264) } \\
\hline Mean & 112 & & \\
\hline Median & 74 & & \\
\hline \multirow{2}{*}{ Cryptococcal Antigen Positivity } & Negative & $425(98.4)$ & \multirow{2}{*}{0.000} \\
\hline & Positive & 7 (1.6) & \\
\hline
\end{tabular}

Table 2. Age group and demographic distribution of cryptococcal antigen among HIV positive patients.

\begin{tabular}{|c|c|c|}
\hline Age Group (Years) & $\mathbf{n}$ & $\%$ \\
\hline $18-28$ & 3 & 42.9 \\
\hline $29-39$ & 4 & 57.1 \\
\hline Total & 7 & 100 \\
\hline \multicolumn{3}{|l|}{ Gender } \\
\hline Male & 0 & 0 \\
\hline Female & 7 & 100 \\
\hline \multicolumn{3}{|l|}{ Educational Qualification } \\
\hline Secondary & 5 & 71.4 \\
\hline HND/BSc & 1 & 14.3 \\
\hline Postgraduate & 1 & 14.3 \\
\hline Total & 7 & 100 \\
\hline
\end{tabular}


Table 3. CD4+ve T cell count, WHO clinical stage and TB status of cryptococcal antigen positive patients.

\begin{tabular}{|c|c|c|}
\hline Parameter & & \\
\hline CD4 Count & $\mathbf{n}$ & $\%$ \\
\hline $0-99$ & 6 & 85.7 \\
\hline $100-199$ & 0 & 0 \\
\hline$\geq 200$ & 1 & 14.3 \\
\hline Total & 7 & 100 \\
\hline \multicolumn{3}{|c|}{ WHO Clinical Stage } \\
\hline I & 3 & 42.9 \\
\hline II & 4 & 57.1 \\
\hline III & 0 & 0 \\
\hline IV & 0 & 0 \\
\hline Total & 7 & 100 \\
\hline \multicolumn{3}{|l|}{ TB Status } \\
\hline Positive & 0 & 0 \\
\hline Negative & 7 & 100 \\
\hline Total & 7 & 100 \\
\hline
\end{tabular}

sizes as well as varying sensitivities and specificities with differing methodologies of used kits. We observed in our study that the majority 6 (85.7\%) of the CrAg positive patients had CD4+ve T cell count less than 100 cells/ul. This finding of $85.7 \%$ CrAg positivity among HIV patients who were severely immunocomprised with CD+veT cell $\leq 100$ cells/ul corroborates previous research reports [24]-[26]. Low CD4+ve T cell level has been found to be the only factor significantly associated with positive serum cryptococcal antigenaemia [22] [24]. The median CD4+ve T cell count among the subjects in our study was 74 cells/ul. This finding is comparable with previous figure of 62 [25] and 60 [26] in previous researches. A previous study revealed that the median CD4+ve T cell count was also reportedly lower in CrAg positive HIV infected patients compared with the CrAg negative [22]. It has also been found that the lower the CD4+ve T cell count, the higher the occurrence of cryptoccocal meningitis in HIV infected patients [27]. Our study is significant in the prevention of cryptococcal meningitis, as it has been shown that the severely immunocompromised HIV patient with CD4+ve T cells $\leq 100$ needs to be screened for CrAg and subsequently placed on pre-emptive treatment depending on the outcome of the tests. We also found out in our study that the WHO clinical stages of CrAg positive patients were 1 and 11 with 3 (42.9\%) and 4 (57.1\%) respectively. None of the CrAg positive HIV infected patients in this study had active tuberculosis. In Uganda, tuberculosis has been reported to be a frequent co-pathogen in patients with cryptococcemia with a 31\% concurrent infection among CrAg positive HIV infected patients [22]. Also in Cape Town, South Africa, a substantial proportion of patients with cryptococcal meningitis were noted to have a history of tuberculosis [4]. We observed a mean age of 38.1 years among the patients, this is compatible with 38.5 years from a previous study [24]. More female patients 248 (57.4\%) than males 184 (42.6\%) were enrolled for our study and all the CrAg positive subjects were female 7 (100\%). This is contrary to previous reports from studies where more males were enrolled and also found CrAg positive [15] [23]. Most of the patients in our study were in age group 29 - 39 years and this observation is similar to findings in a previous research with 24 40 years [27]. The detection of cryptococcal antigen in the serum (CrAg) is clinically relevant and precedes the onset of overt disease as previously documented [28]. Early diagnosis of CM would translate into a reduction in CM-related deaths because patients who receive early antifungal treatment have been shown to have better outcomes than those who receive delayed treatment [29]. Considering the substantial mortality and morbidity associated with CM, preventive interventions should be prioritized. CRAG screening directed at all newly diagnosed HIV-positive patients with CD4+ T-cell counts $<100$ cells/ $\mu$ l is likely to detect most positive cases who are at risk of developing cryptococcal meningitis with high mortality [30]. Treatment of patients with isolated cryptococcal antigenemia has been shown to prevent the development of CM and CM-related death [29]. Prevention of symptomatic CM through early cryptococcal disease detection and pre-emptive treatment should be our focus in Africa as it is cost effective and would reduce mortality. Prevention of the poor outcomes of cryptococcosis 
through routine screening for serum cryptococcal antigen, with early disease detection and prompt treatment, could be a practical approach in resource-limited settings.

\section{Conclusion}

Our study revealed an overall cryptococcal antigenaemia prevalence of $1.6 \%$ among HIV infected adult patients in a Lagos hospital, of which $85.7 \%$ was severely immunocompromised with CD4+ve Tcell count $\leq 100$. Also, we found that WHO clinical stage was not a predicting risk factor for cryptococcal antigenaemia in HIV infection. We recommend the use of point of care test kits which are easy to administer and have excellent sensitivity and specificity and also need no expertise or laboratory infrastructure for the screening of severely immunocompromised patients in resource limited settings such as ours. Targeted screening and subsequent treatment would reduce morbidity and mortality from cryptococcal meningitis among HIV infected patients in our setting.

\section{Acknowledgements}

The authors would like to thank the HIV Clinic Laboratory and Nursing staff for their cooperation during patient recruitment, blood sample collection and rapid testing in this study. We also appreciate IMMY for the donation of CrAg LFA dipsticks which are used for this study.

\section{References}

[1] Park, B.J., Wannemuehler, K.A., Marston, B.J., Govender, N., Pappas, P.J. and Chiller, T.M. (2009) Estimation of the Current Global Burden of Cryptococcal Meningitis among Persons Living with HIV/AIDS. AIDS, 23, 525-530. http://dx.doi.org/10.1097/QAD.0b013e328322ffac

[2] French, N., Gray, K., Watera, C., Nakiyinyi, J., Lugada, E., Moore, M., Lalloo, D., Whitworth, J.A. and Gilks, C.E. (2002) Cryptococcus Infection in a Cohort of HIV-1 Infected Ugandan Adults. AIDS, 16, 1031-1038. http://dx.doi.org/10.1097/00002030-200205030-00009

[3] Corbett, E.L., Churchyard, G.J., Charalambos, S., Samb, B., Moloi, V., Clayton, T.C., Grant, A.D., Murray, J., Hayes, R.J. and De Cock, K.M. (2002) Morbidity and Mortality in South African Goldminers: Impact of Untreated Disease Due to Human Immunodeficiency Virus. Clinical Infectious Diseases, 1, 1251-1258.

[4] Jarvis, J.N. and Harrison, T.S. (2007) HIV-Associated Cryptococcal Meningitis. AIDS, 21, 2119-2129. http://dx.doi.org/10.1097/QAD.0b013e3282a4a64d

[5] Lortholary, O., Poizat, G., Zeller, V., Neuville, S., Boibieux, A., Alvarez, M., Dellamonica, P., Botterel, F., Dromer, F. and Chêne, G. (2006) Longterm Outcome of AIDS Associated Cryptococcosis in the Era of Combination Antiretroviral Therapy. AIDS, 20, 2183-2191. http://dx.doi.org/10.1097/01.aids.0000252060.80704.68

[6] Seboxa, T., Alemu, S., Assefa, A. and Diro, E. (2010) Cryptococcal Meningitis in Patients with Acquired Immunodeficiency Syndrome in Prehaart Era at Gondar College of Medical Sciences Hospital North West Ethiopia. Ethiopian Medical Journal, 48, 237-241.

[7] Lawn, S.D., Bekker, L.G., Myer, L., Orrell, C. and Wood, R. (2005) Cryptococcal Immune Reconstitution Disease: A Major Cause of Early Mortality in a South African Antiretroviral Program. AIDS, 19, 2050-2052. http://dx.doi.org/10.1097/01.aids.0000191232.16111.f9

[8] Etard, J.F., Ndiaye, I., Thierry-Mieg, M., Guèye, N.F., Guèye, P.M., Lanièce, I., Dieng, A.B., Diouf, A., Laurent, C., Mboup, S., Sow, P.S. and Delaporte, E. (2006) Mortality and Causes of Death in Adults Receiving Highly Active Antiretroviral Therapy in Senegal: A 7 Year Cohort Study. AIDS, 20, 1181-1189. http://dx.doi.org/10.1097/01.aids.0000226959.87471.01

[9] Jarvis, J.N., Meintjes, G. and Harrison, T.S. (2010) Outcomes of Cryptococcal Meningitis in Antiretroviral Naive and Experienced Patients in South Africa. Journal of Infection, 60, 496-498. http://dx.doi.org/10.1016/j.jinf.2010.03.007

[10] Jarvis, J.N., Lawn, S.D., Vogt, M., Bangani, N., Wood, R. and Harrison, T.S. (2009) Screening for Cryptococcal Antigenaemia in Patients Accessing an Antiretroviral Treatment Program in South Africa. Clinical Infectious Diseases, 48, 856-862. http://dx.doi.org/10.1086/597262

[11] Micol, R., Lortholary, O., Sar, B., Laureillard, D., Ngeth, C., Dousset, J.P., Chanroeun, H., Ferradini, L., Guerin, P.J., Dromer, F. and Fontanet, A. (2007) Prevalence, Determinants of Positivity and Clinical Utility of Cryptococcal Antigenaemia in Cambodian HIV-Infected Patients. Journal of Acquired Immune Deficiency Syndromes, 45, 555-559. http://dx.doi.org/10.1097/QAI.0b013e31811ed32c

[12] Osazuwa, F., Daisu, J.O., Okuonghae, P.E. and Ugbebor, O. (2012) Screening for Cryptococcal Antigenaemia in AntiRetroviral Naïve AIDS Patients in Benin City, Nigeria. Oman Medical Journal, 27, 228-231. 
http://dx.doi.org/10.5001/omj.2012.51

[13] Dhana, A. (2013) Diagnosis of Cryptococcosis and Prevention of Cryptococcal Meningitis Using a Novel Point-ofCare Lateral Flow Assay. Case Reports in Medicine, 2015, Article ID: 640216. http://dx.doi.org/10.1155/2013/640216

[14] Jarvis, J.N., Harrison, T.S., Lawn, S.D., Meintjes, G., Wood, R. and Clearay, S (2013) Cost Effectiveness of Cryptococcal Antigen Screening as a Strategy to Prevent HIV-Associated Cryptococcal Meningitis in South Africa. PLoS ONE, 8, 1. http://dx.doi.org/10.1371/journal.pone.0069288

[15] Federal Ministry of Health, Nigeria (2010) National Guidelines for HIV/AIDS Treatment and Care in Adolescents and Adults, 7-9.

[16] Federal Ministry of Health (2010) National Guidelines for HIV and AIDS Treatment and Care, 1-10.

[17] Abubakar, A.O., Maikai, B.V., Musa, B.O. and Olayinka, A.T. (2013) Public Health Implications of Cryptococcal Infection among HIV Patients on Antiretroviral Therapy in Hospital in Shika, Nigeria. ISDS 2013 Conference Abstracts.

[18] Rugemalila, J., Maro, V.P., Kapanda, G., Ndaro, A.J. and Jarvis, J.N. (2013) Cryptococcal Antigen Prevalence in HIVInfected Tanzanians: A Cross-Sectional Study and Evaluation of a Point-of-Care Lateral Flow Assay. Tropical Medicine \& International Health, 18, 1075-1079. http://dx.doi.org/10.1111/tmi.12157

[19] CDC (2014) Prevalence and Correlates of Cryptococcal Antigen Positivity among AIDS Patients-United States, 1986-2012. Morbidity and Mortality Weekly Report (MMWR), 63, 585-587.

[20] Igwegbe, A.O. and Ugboaja, J.O. (2010) Rate and Correlates of HIV Serostatus Disclosure among HIV Positive Pregnant Women in Nnewi Southeastern Nigeria. Journal of Medicine and Medical Science, 1, 296-301.

[21] Meyer, A.C.L., Kendi, C.K., Penner, J.A., Odhiambo, N., Otieno, B., Omondi, E., Opiyo, E., Bukusi, E.A. and Cohen, C.R. (2013) The Impact of Routine Cryptococcal Antigen Screening on Survival among HIV-Infected Individuals with Advanced Immunosuppression in Kenya. Tropical Medicine and International Health, 18, 495-503. http://dx.doi.org/10.1111/tmi.12067

[22] Andama, A.O., Saskia, B., Meya, D., Cattamanchi, A., Worodria, W., Davis, J.L., Walter, N.D., Samuel, D.Y., Kalema, N., Haller, B. and Huang, L. (2013) Prevalence and Outcomes of Cryptococcal Antigenemia in HIV-Seropositive Patients Hospitalized for Suspected Tuberculosis in Uganda. JAIDS, 63, 189-194. http://dx.doi.org/10.1097/QAI.0b013e3182926f95

[23] Ganiem, A.R., Indrat, A.R., Wisaksana, R., Meijerink, H., Ven, A., Alisjahbana, B. and Crevel, R. (2014) Asymptomatic Cryptococcal Antigenemia Is Associated with Mortality among HIV-Positive Patients in Indonesia. JAIDS, 17, 18821.

[24] Pongsai, P., Atamasirikul, K. and Sungkanuparph, S. (2010) The Role of Serum Cryptococcal Antigen Screening for the Early Diagnosis of Cryptococcosis in HIV-Infected Patients with Different Ranges of CD4 Cell Counts. Journal of Infection, 60, 474-477. http://dx.doi.org/10.1016/j.jinf.2010.03.015

[25] Chukwuanukwu, R., Manafa, P., Iloghalu, E., Onyenekwe, C., Ifeanyichukwu, M. and Mbamalu, C. (2013) Cryptococcus Neoformans Antigenemia in HIV Positive Pregnant Women Attending a PMTCT Clinic in South-East Nigeria. Journal of Biology, Agriculture and Healthcare, 3, 15-20.

[26] Pongsai, P., Atamasirikul, K. and Sungkanuparph, S. () The Role of Serum Cryptococcal Antigen Screening for the Early Diagnosis of Cryptococcosis in Asymptomatic HIV-Infected Patients. Proceedings of the 5th IAS Conference on HIV Pathogenesis, Treatment and Prevention, Cape Town, 19-22 July 2009, Abstract No. TUPEB120.

[27] Mohammed, S.A. and Chandrasekhar, P. (2009) Study of Cryptococcal Meningitis in HIV Seropositive Patients in a Tertiary Care Centre. JIACM, 10, 110-115.

[28] Chim, B., Piseth, S.S., Heng, V.C., Sopheak, T. and Lynen, L. (2013) Integrated Cryptococcal Antigen Screening and Pre-Emptive Treatment Prior to Initiation of Antiretroviral Treatment in Cambodia. Journal of AIDS \& Clinical Research, 4, 227. http://dx.doi.org/10.4172/2155-6113.1000227

[29] Rajasingham, R., Meya, D.B. and Boulware, D.R. (2012) Integrating Cryptococcal Antigen Screening and Preemptive Treatment into Routine HIV Care. Journal of Acquired Immune Deficiency Syndromes, 59, 85-91. http://dx.doi.org/10.1097/QAI.0b013e31824c837e

[30] Lawn, S.D., Myer, L., Harling, G., Orrell, C., Bekker, L.G. and Wood, R. (2006) Determinants of Mortality and Non Death Losses from an Antiretroviral Treatment Service in South Africa: Implications for Program Evaluation. Clinical Infectious Diseases, 43, 770-776. http://dx.doi.org/10.1086/507095 